\title{
Association of Vascular Endothelial Growth Factor +405G/C Polymorphism with Diabetic Retinopathy among Sudanese Patients
}

\author{
Hoyam Yousif Hussin ${ }^{1 *}$, Waleed Abdelateif Hussein², Sabah AE Ibrahim³ ${ }^{3}$, Sumaya Kambal ${ }^{3}$, \\ Salih Abdelgader Almhdi ${ }^{4}$ and Abd Elkarim A Abdrabo ${ }^{1 *}$ \\ ${ }^{1}$ Clinical Chemistry Department, Al-Neelain University, Khartoum, Sudan
}

${ }^{2}$ Immunology and Molecular Biology Department, Al-Neelain University, Sudan

${ }^{3}$ Department of Bioinformatics and biostatistics, National University-Sudan, Sudan

${ }^{4}$ Department of Clinical Chemistry. The National Ribat University, Sudan

*Corresponding author: Hoyam Yousif Hussin, Clinical Chemistry Department, Faculty of Medical Laboratory Sciences, Al-Neelain University, Khartoum, Sudan. Abd Elkarim A Abdrabo, Clinical Chemistry Department, Faculty of Medical Laboratory Sciences, AlNeelain University, Khartoum, Sudan.

To Cite This Article: Hoyam Yousif Hussin, Waleed Abdelateif Hussein, Sabah AE Ibrahim, Association of Vascular Endothelial Growth Factor +405G/C Polymorphism with Diabetic Retinopathy among Sudanese Patients. Am J Biomed Sci \& Res. 2021 - 11(5). AJBSR.MS.ID.001675.

DOI: 10.34297/AJBSR.2021.11.001675.

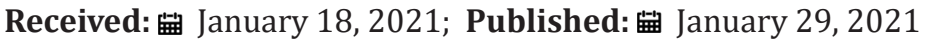

\begin{abstract}
Background: Diabetic retinopathy) DR) is a major cause of new-onset blindness among diabetic adults and is characterized by increased vascular permeability, tissue ischemia, and neo-vascularization. Neovascularization of the retina carries a high risk of blindness because of vitreous hemorrhage and fibrosis. Vascular Endothelial Growth Factor (VEGF), originally known as vascular permeability factor (VPF), is a signal protein produced by cells that stimulates the formation of blood vessels. Polymorphisms within the VEGF gene lead to differences in VEGF expression between individuals and could influence the etiology of a variety of pathologic conditions with which VEGF has been associated.
\end{abstract}

Aim: The aim of this study is to investigate $+405 \mathrm{G} / \mathrm{C}$ polymorphism of VEGF gene in Sudanese patients with type 2 diabetes mellitus (T2DM) and to evaluate its relationship with the development and improvement of diabetic retinopathy.

Materials and Methods: A total of 189individuals subjects divided to 3 groups (diabetics with DR, diabetics without DR and health individuals) were observed to determine the relationship between DR and +405 G/C VEGF gene polymorphism.

Results: This study revealed that patients with GC genotypes are about $57.6 \%$ at risk ( $95 \%$ CI 1.022-2.431) to develop DR, while the risk is about $40 \%$ (95\% CI 0.404-0.893) in DM patients without DR than those without GC genotype.

Conclusion: These results indicated that +405 VEGF G/C polymorphism could be used in the evaluation, development, and progression of DR.

\section{Introduction}

Diabetes mellitus (DM), commonly known as diabetes, is a group of metabolic disorders characterized by a high blood sugar level over a prolonged period [1]. If left untreated, diabetes can cause many complications including diabetic ketoacidosis, hyperosmolar hyperglycaemic state and ultimately may lead to death [2,3]. Serious long-term complications include cardiovascular disease, stroke, chronic kidney disease, foot ulcers, damage to the nerves, damage to the eyes and cognitive impairment $[2,4]$. These complications 
impose burdens on the health care systems worldwide. There are three main types of diabetes mellitus: type 1 , type 2 , and Gestational diabetes [2]. This categorization is according to the pathogenic processes involved which are ranged from autoimmune destruction of beta cells of the pancreas that leads to the insulin deficiency developing Type 1 diabetes Mellitus, aka insulindependent diabetes mellitus (IDDM), toa combination of resistance to insulin action and inadequate insulin secretion which led to the development of Type 2 diabetes mellitus [2,3,5]. Type 2 diabetes is also known non-insulin-dependent diabetes mellitus(NIDDM) or adult-onset diabetes and it has become the common type among Sudanese patients and of major concern to diabetologists. The third type, gestational diabetes mellitus (GDM), occurs when pregnant women without a previous history of diabetes develop high blood sugar levels [2]. One of the most common long-term complications of diabetes is diabetic retinopathy (DR) which may cause vision impairment [6]. It often refers to retinal vascular disease, or damage to the retina caused by abnormal blood flow. Frequently, it is an ocular manifestation of systemic disease as seen in diabetes or hypertension [7]. The development of retinopathy can be broken down into proliferative and non-proliferative types. Both types cause disease by altering the normal blood flow to the retina through different mechanisms [8].

Vascular Endothelial Growth Factor (VEGF), originally known as vascular permeability factor (VPF), [9] is a signal protein produced by cells that stimulates the formation of blood vessels. They are important signalling proteins involved in both vasculogenic and angiogenesis. It is part of the system that restores the oxygen supply to tissues when blood circulation is inadequate such as in hypoxic conditions [10]. Serum concentration of VEGF is high in diabetes mellitus [11]. The VEGF's normal function is to create new blood vessels during embryonic development, new blood vessels after injury, muscle following exercise, and new vessels (collateral circulation) to bypass blocked vessels. It can stimulate angiogenesis, enhance collateral vessel formation, and increase the permeability of the microvasculature [12,13]. Diabetic micro vascular changes in the retina lead to hypoxia, which stimulates production of VEGF [14] This protein is believed to play a significant role in the development of DR by inducing hyper permeability of retinal vessels, breakdown of the blood-retinal barrier and neovascularization [15.16]. These complications can arise because of abnormal barrier function of new vessels, leading to intraregional hemorrhage and exudation. Additionally, New blood vessels with increased fragility leading to sudden severe loss of vision due to vitreous hemorrhage.

\section{PCR test}

Genomic DNA was extracted using quinidine chloride method and the targeted region was amplified in a final volume of $26 \mu \mathrm{l}(3 \mu \mathrm{l}$ Genomic DNA $+1.5 \mu \mathrm{lF}$-primer $+5 \mu \mathrm{l}$ master mix +0.5 enhancer + 16 DDW). The polymerase chain reaction was set for denaturation at $94^{\circ} \mathrm{C}$ for $4 \mathrm{~min}$ followed by 35 cycles of denaturation at $94^{\circ} \mathrm{C}$ for 45 seconds, annealing at $58^{\circ} \mathrm{C}$ for $1 \mathrm{~min}$ and extension at $72^{\circ} \mathrm{C}$ for $1 \mathrm{~min}$ and define extension was at $72^{\circ} \mathrm{C}$ for $5 \mathrm{~min}$ and then hold at $4{ }^{\circ} \mathrm{C}$ for in definite time. Then the amplification products were separated by electrophoresis through $2 \%$ agarose gel stained with ethidium bromide ,then for the VEGF+ +405 polymorphism the PCR product was digested with the BsmFI restriction nuclease (Bio labs) [18].Digestion conditions that give best result $9.3 \mu$ l of water were added to $2 \mu \mathrm{l}$ of NEB buffer, 0.2BSA, $8 \mu \mathrm{l}$ of PCR product and $0.5 \mu \mathrm{l}$ BsmFI enzyme to a final volume of $20 \mu \mathrm{l}$, those were mixed and incubated at $65^{\circ} \mathrm{C}$ for 3 hours. The uncut fragment was 300 base pairs (bp) (Callele) and G allele) digestion products were 200bp and $100 \mathrm{bp}$ approximately.

\section{Statistical Analysis}

Data was examined using statistical package of social science (IBMSPSS version 20.0) for windows software package. A P value of $\leq 0.05$ was interpreted as statistically significant. Categorical variables, alleles and genotypes frequency were analyzed using a Pearson's Chi square test or Fisher's Exact Test. The strength of significant was done by calculating the contribution to chi square of each cell using adjusted residuals $P$ values (adjusted $P$ value $=0.05$ / number of new adjusted residuals or cells). Odds and risk ratios with $95 \%$ confidence intervals were estimated for the effect of high-risk alleles and genotypes. Comparison of groups was done by Kruskal Wallis test and the post hoc was done using Independent samples Kruskal Wallis. Correlation between quantitative variables was done by Spearman's rank correlation test.

\section{Results}

This study included 189 subjects divided into three groups of 63 subjects each. Regarding the gender in the present study there was $55.6 \%, 41.3 \%$ and $54 \%$ males, and $44.4 \%, 58.7 \%$ and $46 \%$ females in healthy, DM without DR and DM with DR groups, respectively. The healthy group had age mean of $62.24 \pm 1.74$, the DM group had age mean of $2.08 \pm 1.54$ and the DR group had age mean of $67.92 \pm 1.13$. The HBA1c levels had the highest mean $(9.94 \pm 0.22 \%)$ in the DR group followed by DM without DR $(8.58 \pm 0.19 \%)$ compared with healthy control group $(4.89 \pm 0.11 \%)$. Similarly, the glucose levels in the DR group had the highest mean | $(190.10 \pm 8.04)$ | followed by the

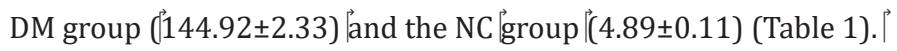

\section{Genotypes and Alleles Frequency}

Comparison of Genotypes frequency between the three Groups: The present results indicated that all groups were significantly different form each other (Chi square P. value = 0.00001), (Table 5).

Likewise, the GC genotype percentage $(74.6 \%)$ in the DR group was the highest compared to the normal and DM without DR groups (34.3\% and $19.6 \%$ respectively). Also, the CC genotype 
percentage $(60.9 \%)$ in DM group was the highest compared to the normal and DR groups (13\% and $26.1 \%$ respectively), and the GC genotype was significantly (adjusted $p$ value $=0.00279$ ) less than expected. In addition, the DR group showed the less prevalence of the GG genotype compared to the other groups (these results were considered as the most significant results after measuring the contribution of cells to chi square with an adjusted $\mathrm{p}$ values) (Table 2).

Table 1: Descriptive analysis of study population.

\begin{tabular}{|c|c|c|c|c|c|}
\hline \multirow{2}{*}{ Variables } & & \multirow{2}{*}{ All groups } & NC & DM & \multirow{2}{*}{ DR } \\
\cline { 2 - 5 } & Descriptive showed as & 95 & $55.60 \%$ & $41.30 \%$ & $54 \%$ \\
\hline \multirow{2}{*}{ Gender } & Males $\%$ & 94 & $44.40 \%$ & $58.70 \%$ & $46 \%$ \\
\cline { 2 - 5 } & Females $\%$ & $64.08 \pm .88$ & $62.24 \pm 1.74$ & $62.08 \pm 1.54$ & $67.92 \pm 1.13$ \\
\hline AGE & Mean \pm SE. & $7.80 \pm .19$ & $4.89 \pm 0.11$ & $8.58 \pm .19$ & $9.94 \pm .22$ \\
\hline HBA1c level & Mean \pm SE. & $142.04 \pm 4.07$ & $91.10 \pm 1.10$ & $144.92 \pm 2.33$ & $190.10 \pm 8.04$ \\
\hline Total number & Mean \pm SE. & 189 & 63 & 63 & 63 \\
\hline
\end{tabular}

Table 2: The frequency of Genotypes between the Normal, DM and DR groups.

\begin{tabular}{|c|c|c|c|c|c|}
\hline \multirow{2}{*}{\multicolumn{2}{|c|}{$\begin{array}{c}\text { Groups } \\
\text { GC }\end{array}$}} & \multicolumn{3}{|c|}{ Genotypes } & \multirow{3}{*}{$\begin{array}{c}\text { Total } \\
63\end{array}$} \\
\hline & & \multirow{2}{*}{$\begin{array}{c}\text { GG } \\
35\end{array}$} & \multirow{2}{*}{$\begin{array}{l}\text { CC } \\
25\end{array}$} & \multirow[b]{2}{*}{3} & \\
\hline \multirow{4}{*}{ Normal } & Count & & & & \\
\hline & Expected Count & 34 & $\begin{array}{c}2 \\
1.3\end{array}$ & 7.7 & 63 \\
\hline & Within group \% & $55.60 \%$ & $39.70 \%$ & $4.80 \%$ & $100 \%$ \\
\hline & Within genotype $\%$ & $34.30 \%$ & $39.10 \%$ & $13.00 \%$ & $33.30 \%$ \\
\hline \multirow{4}{*}{ DM } & Count & $20 * * a$ & 29 & $14^{* *} \mathrm{~d}$ & 63 \\
\hline & Expected Count & 34 & 21.3 & 7.7 & 63 \\
\hline & Within group \% & $31.70 \%$ & $46.00 \%$ & $22.20 \%$ & $100 \%$ \\
\hline & Within genotype $\%$ & $19.60 \%$ & $45.30 \%$ & $60.90 \%$ & $33.30 \%$ \\
\hline \multirow{4}{*}{ DR } & Count & $47^{* *} \mathrm{~b}$ & $10^{* *} \mathrm{c}$ & 6 & 63 \\
\hline & Expected Count & 34 & 21.3 & 7.7 & 63 \\
\hline & Within group \% & $74.60 \%$ & $15.90 \%$ & $9.50 \%$ & $100 \%$ \\
\hline & Within genotype $\%$ & $46.10 \%$ & $15.60 \%$ & $26.10 \%$ & $33.30 \%$ \\
\hline \multirow{4}{*}{ Total } & Count & 102 & 64 & 23 & 189 \\
\hline & Expected Count & 102 & 64 & 23 & 189 \\
\hline & $\%$ within Groups & $54.00 \%$ & $33.90 \%$ & $12.20 \%$ & $100.00 \%$ \\
\hline & $\%$ within genotype & $100.00 \%$ & $100.00 \%$ & $100.00 \%$ & $100.00 \%$ \\
\hline
\end{tabular}

Note*: ** Mostly contributed to chi square (adjusted $P$ value 0.005 ) ( $p$ values $a=0.00001, b=0.00006, c=0.00022, d=0.00279$ )

ODM (Diabetes Mellitus) DR (Diabetic Retinopathy)

Table 3: Alleles Frequency in studied groups

\begin{tabular}{|c|c|c|c|c|c|}
\hline \multirow{2}{*}{\multicolumn{2}{|c|}{$\begin{array}{c}\text { Allele } \\
\text { NC }\end{array}$}} & \multicolumn{3}{|c|}{ Groups } & \multirow{2}{*}{ Total } \\
\hline & & DM & DR & & \\
\hline \multirow{2}{*}{$\mathrm{C}$} & Within allele $\%$ & $24.20 \%$ & $38.40 \%$ & $37.40 \%$ & $100.00 \%$ \\
\hline & Within group $\%$ & $26.10 \%$ & $35.80 \%$ & $45.70 \%$ & $35.50 \%$ \\
\hline
\end{tabular}

Alleles Frequency in All Three Groups: The current study observed that there is a significant difference (Chi square, $\mathrm{P}$ value $=0.027$ ) in allele frequency among all groups. The $G$ allele was dominant (64.5\%) over the C allele (35.5\%). The C allele has $24.2 \%$ in NC group, $38.4 \%$ in DM group and $37.4 \%$ in DR group. While the G allele had 73.9\%in NC group, $64.2 \%$ in DM group and $54.3 \%$ in DR group (Table 3). 


\begin{tabular}{|c|c|c|c|c|c|}
\hline \multirow{2}{*}{ G } & Within allele \% & $37.80 \%$ & $37.80 \%$ & $24.40 \%$ & $100.00 \%$ \\
\cline { 2 - 6 } & Within group \% & $73.90 \%$ & $64.20 \%$ & $54.30 \%$ & $64.50 \%$ \\
\hline
\end{tabular}

Comparison of HBA1c Levels Between All Groups: The results have shown that there is a significant difference within all three groups (Independent samples Kruskal Wallis test, $\mathrm{P}$ Value $=$ 0.001). Also, a significant difference was observed between groups (DM-DR, P value 0.009) (DM-No, P value 0.001) (No-DR, P value 0.001). The DR group showed the highest HBA1c levels followed by the DM group and the Normal group respectively (Figure 1).

Comparison of glucose levels between all groups: The study has demonstrated that there is a significant difference within all three groups (Independent samples Kruskal Wallis test, P Value
$=0.001)$. Also, a significant difference was observed between groups (DM-DR P value 0.022) (DM-No P value 0.001) (No-DR P value (Figure 2) The amplification PCR product was approximately $300 \mathrm{bp}$ as figure (3) revealed $[17,19]$ containing the targeted site (Figure 3).

Figure 4 shows the restriction digestion pattern that obtained in this study after digestion of PCR product with restriction enzyme. The revealed genotypes of the subjects were divided into 3 groups based on the presence or absence of polymorphism:

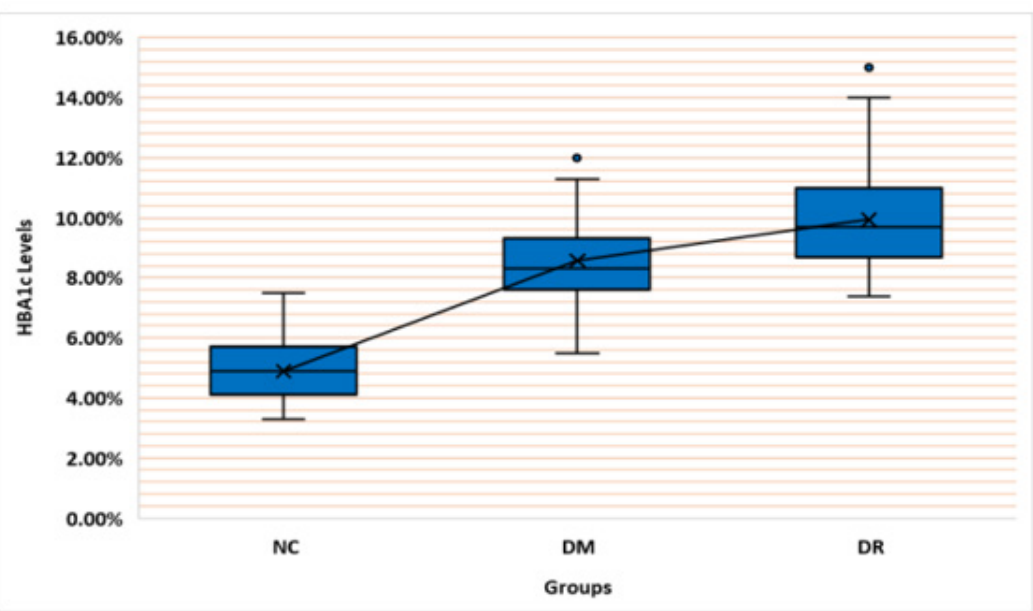

Figure 1: The frequency of HBA1c levels in all three groups (Normal, DM and DR).

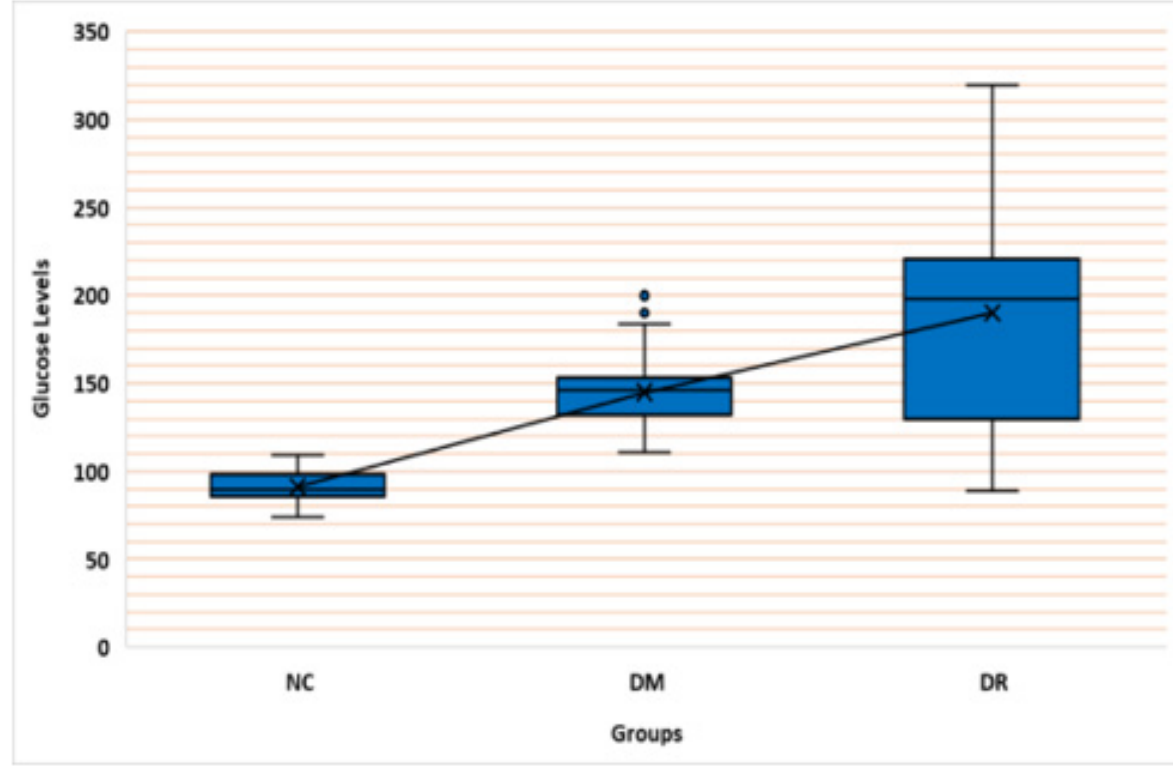

Figure 2: The frequency of Glucose levels in all groups (Normal, DM and DR). 


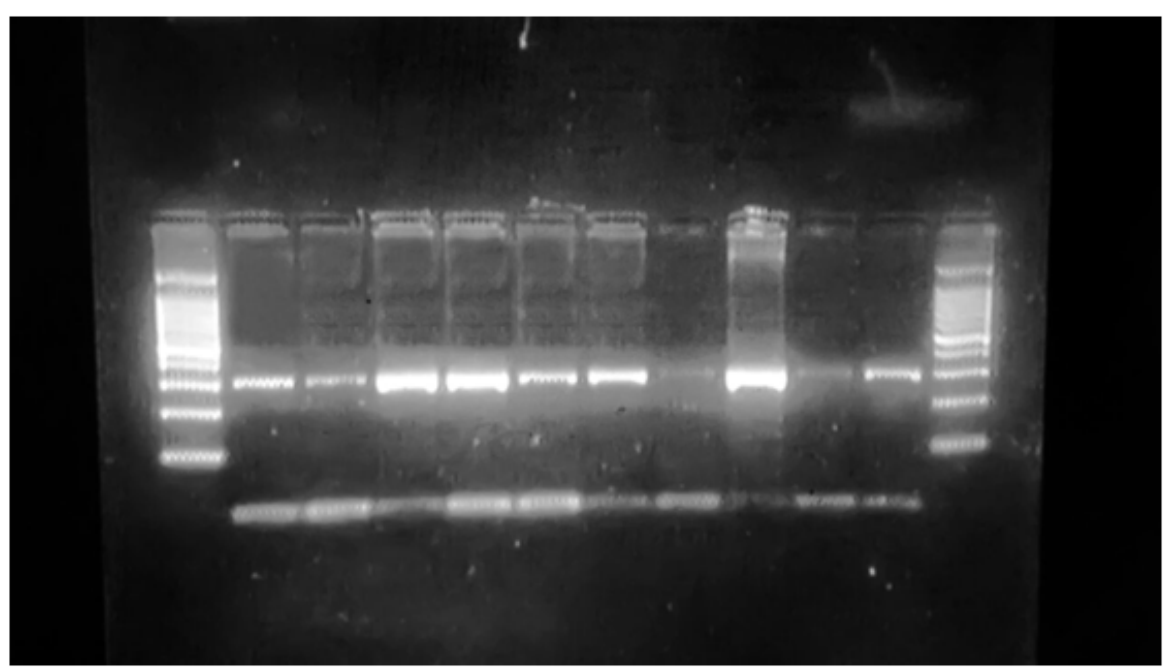

Figure 3: PCR product, $2 \%$ agarose, , and for 40 minute ( $7 \mu$ l of DNA loaded in each well).

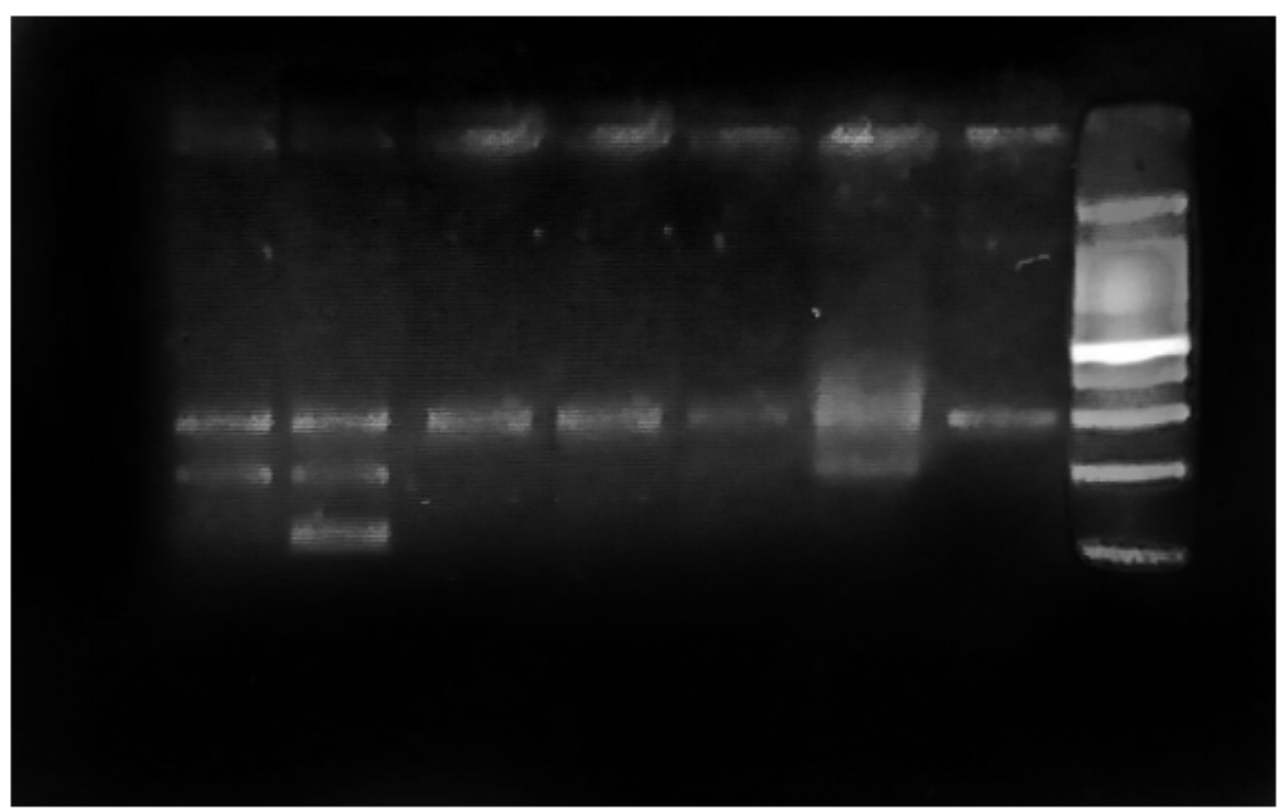

Figure 4: Restriction digestion of PCR products demonstrating the patterns of digestion in different genotypes of VEGF +405 G $>C$ polymorphism on $2 \%$ agarose, and for 50 minutes ( $8 \mu$ l of DNA loaded in each well).

1. Two bands (200 bp and $100 \mathrm{bp}$ ) is wild-type homozygote (GG); absence of polymorphism.

2. One band; the uncut fragment (300 bp) is variant homozygote (CC); presence of polymorphism.

3. Three bands $(300 \mathrm{bp}, 200 \mathrm{bp}$, and100 bp) is variant and wild type heterozygote (GC); presence of polymorphism (Figure 4).

\section{Discussion}

VEGF is believed to play a significant role in the development of DR by inducing hyper permeability of retinal vessels, breakdown of the blood-retinal barrier and neovascularization $[20,21]$. Complications can arise because of abnormal barrier function of new vessels, leading to intra retinal hemorrhage and exudation. New blood vessels have increased fragility leading to sudden severe loss of vision due to vitreous hemorrhage. orphismsmightbeausefulpredictivemarkerforthedevelopmentand progression of diabetic retinopathy at an earlier stage [22].

This study revealed that patients with GC genotypes will be $57.6 \%$ higher at risk (95\% CI 1.022-2.431) to develop DR and 40 \% lower at risk (95\% CI 0.404-0.893) to develop DM than those without GC genotype. While patients with CC genotypes will be 
83.2 \% higher at risk (95\% CI 1.354-2.479) to develop DM and 36.8 $\%$ higher at risk (95\% CI .0.832-2.252) to develop DR than those without CC genotype. In addition, patients with GG genotypes will be $13.7 \%$ higher at risk (95\% CI 0.803-1.610) to develop DM and $50.9 \%$ Lower at risk (95\% CI .282 - .852) to develop DR than those without GG genotype.

This agrees with the results of Ray et al. [23]; it was observed that the presence of the $\mathrm{G}$ allele is a risk marker for developing retinopathy as well as $\mathrm{PAD}$, suggesting a potential association between this allele and an increase in activity in the promoter region of the gene. These data differ from those and our study which described by in Szaflik et al. [24] which the C allele of +405 genes was associated with an increased risk of DR.

On the other hand, Watson et al. [25] Found is in a coincidence with our study in which the $G$ allele at position +405 affects the transcriptional activity and increases VEGF production in peripheral blood mononuclear cells in response to lipopolysaccharide. They also showed a dose-dependent effect of the G allele.

This study observed that the GC genotype and the G allele of +405 G/C polymorphism of VEGF gene are increased related to the severity of DR (PDR and DME) in Sudanese type 2 diabetic patients suffering from DR than those without the disease. This is in accordance with other results where the SNP +405 G/C (rs: 2010963) has previously been associated with DR in other populations [26-28]. However, to our knowledge, there are no studies regarding the behavior of this SNP in the Sudanese diabetic population suffering from DR.

Some SNPs of VEGF gene such as $+405 \mathrm{G} / \mathrm{C}$ polymorphism impact VEGF protein expression and has functional significance on VEGF protein production [25]. These data have no suspicion call for a possibility that $+405 \mathrm{C} / \mathrm{C}$ VEGF in diabetics could be engaged in DR development and severity through increasing VEGF expression and hence production.

Emerging data show that anti-VEGF therapy, which is less destructive than laser, can reverse the diabetic retinopathy. This supports the suggestion of the role of this SNP in the pathogenesis of DR [29,30]. Moreover, the American Academy of Ophthalmology (AAO) preferred practice pattern committee now stated that there is sufficient evidence for the treatment of DR with anti-VEGF treatment [31].

\section{Conclusion}

We showed for the first time in Sudan diabetic population that the VEGF $+405 \mathrm{G} / \mathrm{C}$ polymorphism is associated with DR as a genetic marker for predicting DR in type 2 Sudanese diabetics.

\section{References}

1. (2014)) About diabetes. World Health Organization.

2. (2013) Diabetes Fact sheet $N^{\circ} 312$. World Health Organization.
3. Norman A, Henry H (2015) Hormones Elsevier. pp. 136-137.

4. Saedi E, Gheini MR, Faiz F, Arami MA (2016) Diabetes mellitus and cognitive impairments. World J Diabetes 7(17): 412-422.

5. (2012) RSSDI textbook of diabetes mellitus (Revised 2nd Ed.). Jaypee Brothers Medical Publishers. Pp. 235.

6. (2017) Definition of RETINOPATHY. www.merriam-webster.com.

7. (2012) American Academy of Orgasms. Retina and vitreous (2011-2012 Ed.) Pp. 271.

8. Carol, Porth, Glenn Matfin, Carol Porth (2009) Pathophysiology: concepts of altered health states. Wolters Kluwer Health/Lippincott Williams \& Wilkins Pp. 756.

9. D R Senger, S J Galli, A M Dvorak, C A Perruzzi, V S Harvey, et al. (1983) Tumor cells secrete a vascular permeability factor that promotes accumulation of ascites fluid. Science 219(4587): 983-985.

10. Palmer Biff F, Clegg Deborah J (2014) Oxygen sensing and metabolic homeostasis. Mol Cell Endocrinol 397(1-2): 51-57.

11. M E Cooper, D Vranes, S Youssef, S A Stacker, A J Cox, et al. (1999) Increased Renal Expression of Vascular Endothelial Growth Factor (VEGF) and Its Receptor VEGFR-2 in Experimental Diabete. Diabetes 48 (11): 2229-2239.

12. Ferrara N, Gerber HP (2001) The role of vascular endothelial growth factor in angiogenesis. Acta Haematol 106(4): 148-156.

13. Ferrara N, Davis Smyth T (1997) The biology of vascular endothelial growth factor. Endocr Rev 18(1): 4-25.

14. Aiello LP Avery RL Arrigg PG, BA Keyt, HD Jampel, et al. (1994) Vascular endothelial growth factor in ocular fluid of patients with diabetic retinopathy and other retinal disorders. N Engl J Med 331(22): 14801487.

15. (2017) International Diabetes Federation. IDF diabetes atlas (8th Ed.). Brussels: International Diabetes Federation.

16. Boutayeb A, Lamlili MEN, Boutayeb W, Abdellatif Maamri, Abderrahim Ziyyat, et al. (2012) The rise of diabetes prevalence in the Arab region. Open J Epidemiol 2(2): 55-60.

17. Silvia Bleda, Joaquin De Haro, Cesar Varela, Leticia Esparza, Antonio Ferruelo, et al. (2012) Vascular end othelial growth factor polymorphisms are involved in the late vascular complications in Type II diabetic patients. Diab Vasc Dis Res 9(1): 68-74.

18. Gentilini D, Somigliana E, Vigano P, Michele Vignali, Mauro Busacca, et al. (2008) The vascular endothelial growth factor405G/C polymorphism in endometriosis. Hum Reprod 23(1): 211-215.

19. Buraczynska M, Ksiazek P, Baranowicz Gaszczyk I, Lucyna Jozwiak (2007) Association of the VEGF gene polymorphism with diabetic retinopathy in type 2 diabetes patients. Nephrol Dial Transplant 22(3): 827-832.

20. Ferrara N (2001) Role of vascular endothelial growth factor in regulation of physiological angiogenesis. Am J Physiol Cell Physiol 280(6): C1358-C1366.

21. Ribatti D (2005) The crucial role of vascular permeability factor/ vascular endothelial growth factor in angiogenesis: a historical review. Br J Haematol 128(3): 303-309.

22. Chun MY, Hwang HS, Cho HY, Ha Jung Chun, Jung Taek Woo, et al. (2010) Association of vascular endothelial growth factor polymorphisms with non-proliferativeandproliferative diabetic retinopathy. J Clin Endocrinol Metab 95(7): 3547-3551.

23. Ray, D, Mishra, M, Ralph, S, Read, J, Davies, R, et al. (2004) Association of the VEGF gene with proliferative diabetic retinopathy but not proteinuria in diabetes. Diabetes 53(3): 861-864. 
24. Szaflik JP, Wysocki T, Kowalski M, Majsterek I, Borucka AI, et al. (2008) An association between vascular endothelial growth factor gene promoter polymorphisms and diabetic retinopathy. Graefes Arch Clin Exp Ophthalmol 246(1): 39-43.

25. Watson CJ, Webb NJ, Bottomley MJ, Brenchley PE (2000) Identification of polymorphism within the vascular endothelial growth factor (VEGF) gene: correlation with variation in VEGF protein production. Cytokine. 12(8): 1232-1235

26. Buracznska M, Ksiazek P, Baranowicz Gaszczyk I, Jozwiak I (2007) Association of the VEGF gene polymorphism with diabetic retinopathy in type 2 diabetic patients. Nephrol Dial Transplant 22(3): 827-832.

27. Badre S, Al Awadi SJ, Algenab AA (2013) Vascular endothelial growth factor $+405 \mathrm{G} / \mathrm{C}$ polymorphism and diabetic retinopathy. Int J Adv Res 1(8): 278-286.
28. Fan X, Wu Q Li Y, Hao Y, Ning N, et al. (2014) Association of polymorphism in the VEGF gene and its serum levels within diabetic retinopathy in Chinese patients with type2 diabetes: cross sectional study. Chin Med J (Engl) 127(4): 651-657.

29. Gupta N, Mansoor S, Sharma A, Sapkal A, Sheth J, et al. (2013) Diabetic retinopathy and VEGF. Open Ophthalmol J 7: 4-10.

30. Wyckoff CC, Chakravarthy U, Campochiaro PA, Clare Bailey, Ken Green, et al. (2017) Long term effects of intravitreal $0.19 \mathrm{mg}$ fluocinoloneacetonide implant on progression and regression of diabetic retinopathy. Ophthalmology 24(4): 440-449.

31.(2017) Diabetic retinopathy updated. American Academy of ophthalmology. https://www.aao.org/preferred-practice pattern. 